\title{
Is landscape of fear of macroinvertebrate communities a major determinant of mesopredator and prey activity?
}

\author{
Raoul Manenti* and Benedetta Barzaghi \\ Department of Environmental Science and Policy, univeristà degli Studi di Milano, Via Celoria, 26, 20133 Milano, Italy
}

Received: 1 November 2019 / Accepted: 30 December 2019

\begin{abstract}
Macroinvertebrate foragers play an important role on the trophic structures of freshwater environments, and multiple trophic levels occur among macroinvertebrate communities providing very interesting scenarios for testing scientific hypotheses. One of the most intriguing aspect to understand is the role played by the landscape of fear (LOF) on macrobenthos density and activity. With this pilot study we wanted to test if LOF at the macrobenthos community levels plays a role in determining the density of both prey and mesopredators. During two consecutive years, we evaluated, with both day and night surveys, the density of two mesopredator triclad species and of one detritivore prey crustacean species, and we compared them to the number of respective predators occurring in the macroinvertebrate community. LOF levels at the macroinvertebrate community did not reduce the abundance of the target taxa. One of the triclad species was instead positively related to the levels of LOF assessed for it on the basis of the available knowledge. The broad implication of the research is that the abundance of freshwater macroinvertebrates is not mainly linked to the predation risk at the community level, suggesting that also for researches on macrobenthos LOF analyses should take in consideration the role of top predators.
\end{abstract}

Keywords: Seepage / triclad / isopod / behaviour / predator

Résumé - Le « landscape of fear » des communautés de macroinvertébrés est-il un déterminant majeur de l'activité des méso-prédateurs et des proies ? Les macroinvertébrés butineurs jouent un rôle important sur les structures trophiques des milieux d'eau douce, et de multiples niveaux trophiques se retrouvent parmi les communautés de macroinvertébrés, ce qui offre des scénarios très intéressants pour vérifier des hypothèses scientifiques. L'un des aspects les plus intrigants à comprendre est le rôle joué par le « landscape of fear » (LOF) sur la densité et l'activité du macrobenthos. Avec cette étude, nous voulions vérifier si le LOF au niveau des communautés de macrobenthos joue un rôle dans la détermination de la densité des proies et des méso-prédateurs. Pendant deux années consécutives, nous avons évalué, au moyen de relevés de jour et de nuit, la densité de deux espèces de tricladés méso-prédateurs et d'une espèce de crustacé proie détritivore, et nous les avons comparées au nombre de prédateurs correspondants présents dans la communauté de macroinvertébrés. Les niveaux du LOF dans la communauté des macroinvertébrés n'ont pas réduit l'abondance des taxons ciblés. L'une des espèces de tricladés était plutôt liée de façon positive aux niveaux de LOF évalués pour elle sur la base des connaissances disponibles. La recherche a eu pour conséquence générale que l'abondance des macroinvertébrés d'eau douce n'est pas principalement liée au risque de prédation au niveau de la communauté, ce qui laisse entendre que, pour les recherches sur le macrobenthos également, les analyses du LOF devraient tenir compte du rôle des prédateurs supérieurs.

Mots clés : Fuite / triclade / isopode / comportement / prédateur

The communities of freshwater invertebrates are regarded as fundamental indicator of the status and pollution of freshwater habitats. Several factors may determine differences in macroinvertebrate activity and distribution; in general, all the aspects under the constraints of Darwinian natural selection

\footnotetext{
*Corresponding author: raoulmanenti@gmail.com
}

as food availability, predation risk and other inter- and intraspecific interactions may concur to determine differences in macroinvertebrate species density (Elliott, 2002). While food availability is a well-recognised element regulating macrobenthos abundance and diel activity (Elliott, 2002; Fiser et al., 2007), in freshwater habitats less attention is paid to the predation risk that may involve different taxa. In particular, one 
of the most intriguing aspect to understand is the role played by landscape of fear (LOF) on macrobenthos density and activity: macroinvertebrate foragers play an important role on the trophic structures of freshwater environments, and multiple trophic levels occur among macroinvertebrate communities furnishing several opportunities to study LOF effects (Marino et al., 2016). A forager has to usefully adopt strategies to forage based on the type of risk it is likely to face (Matassa and Trussell, 2011).

To assess if LOF affects the macrobenthos diel activity, we studied environments with similar aquatic top predator presence, such as day active visual predators and night active wanderer predators and we focused only on the LOF at the macroinvertebrate community level.

First of all, we tested if LOF varied between day and night conditions; second, we evaluated the relationship between LOF and density of both target mesopredator and prey invertebrate species. In particular, we tested two hypotheses:

- fear hypothesis: LOF affects prey and/or mesopredator density and activity;

- no fear hypothesis: the density of predator and/or prey species varies with day/night conditions notwithstanding the levels of LOF.

In particular, during two consecutive years, we evaluated, with both day and night surveys, the density of two mesopredator triclad species and of one detritivore prey crustacean species comparing it to the predator occurring in the whole macroinvertebrate community.

We performed the study in Lombardy (NW Italy). We studied four "fontanili"; springs forming lentic habitats fed by groundwater flow. Fontanili are springs anciently managed by humans pushing tubes in the substrate to collect groundwater and ease their flow toward the surface (Balderacchi et al., 2016). We performed 8 transects ( 2 for each site). The transects were all $1 \mathrm{~m}$ wide, but varied in length depending on the site features (length average $\pm \mathrm{SE}=4.3 \pm 0.7 \mathrm{~m}$ ).

During winter months, from December 2017 to February 2018 and from December 2018 to February 2019, we performed for each site 12 repeated surveys both during day and night (6 surveys during night and 6 during day). During surveys in each site we first assessed visually the occurrence and the number of the target taxa such as crustaceans of the species Asellus aquaticus and planarians of the species Polycelis nigra and Dendrocoelum lacteum along two transects per site.

During each survey, in each transect after 20 min of visual encounter numbering of the target organisms we sampled the whole macrobenthos community using a dip-net. Visual encounters allowed recording the number of active individuals only. Net samplings lasted $10 \mathrm{~min}$ in each transect and were performed by intense movement of the substrate. All the collected organisms were released in the transect of origin after having been numbered and recognised at species, genus or family level according to the guidelines for the Italian Biotic Index assessment (Ghetti 1997). We also visually assessed the occurrence of wanderer top predator species like fish. From each survey we kept a minimum 4 days of interval. During surveys we also recorded maximum illuminance of the water surface (with a PCE EM882 luxmeter) and water temperature.
LOF assessment considered the taxa collected through the dipnetting of the substrate at each sampling session. LOF was calculated using the number of potential predator taxa for each target species occurring in the transects: we divided the number of occurring predators per the total number of taxonomical units collected. Predator assessment was based on the information available in the literature (Ghetti, 1997; Reynoldson and Young, 2000; Tachet, 2010).

To test if LOF was different between sites and day/night conditions, we developed a Linear Mixed Model (LMM) using the log transformed levels of LOF as dependent variables and the transect identity and the period (day/night) as fixed factors; we considered also the year of sampling as random factor. Through a Wald F test we assessed the significance of the fixed factors composing the model.

We then used random-effect generalized mixed models (GLMMs) to assess the relationships between the relative abundance of the target taxa and the LOF (Barker et al., 2017). In particular, we used a negative binomial distribution to account for over dispersion as, especially for planarians, we had different 0 occurrences. As a dependent variable, we considered the number of active individuals of the target taxa observed for each transect at each survey. We included the moment of observation (day/night) and the sampling method (visual/net) as covariates. We included the year of survey, the number of survey and the transect as random factors.

GLMMs and LMMs were run in $\mathrm{R}$ environment ( $\mathrm{R}$ Development Core Team, 2018) using a negative binomial error, using the package glmmTMB, lmerTest and car (Brooks et al., 2017).

Considering the whole samplings, Polycelis nigra was the most abundant species (on average $( \pm \mathrm{SE}) 34.9 \pm 8.5$ individuals per sampling). Considering night samplings only the average number of Asellus aquaticus observed overcame the average number of $P$. nigra $(18 \pm 5.2 \mathrm{~A}$. aquaticus individuals' vs. $16.9 \pm 5.2 P$. nigra individuals).

Water temperature was on average $( \pm \mathrm{SE}) 12.17^{\circ} \mathrm{C} \pm$ $0.19^{\circ} \mathrm{C}$; a significant difference, assessed through ANOVA and post-hoc tukey test was observed only between two of the sites $(F=3.2 ; P=0.03)$. Maximum illuminance in fontanili during sunny days was around 40000 lux and ranged between 0,01 and 0,1 lux during night with no significant differences between sites. Wanderer top predator taxa such as fish (species observed: Telestes souffia muticellus, young Esox lucius, Perca fluviatilis, Padogobius bonelli and Gobio gobio) and the alien freshwater crayfish Procambarus clarkii were recorded in all the sites with at least one observation in the proximity or inside the transects during each year of monitoring. While fish were observed both during day and night, crayfish were detected mainly during night. In the transects we recorded globally 13 macroinvertebrate predator taxa at which for our crustacean target species must be added the two planarians target species. On average $( \pm \mathrm{SE})$, considering all the predator taxa, the number of the potential predator individual for our crustacean target species was of $1.25 \pm 0.34$ individuals per net sampling.

LOF levels differed among sites (for both crustacean and planarians LOF levels: $F>5.7 ; P<0.001$ ), but not between day/night conditions (for both crustacean and planarians LOF levels: $F<0.22 ; P>0.64)$. Dendrocoelum lacteum was significantly more abundant during night (Tab. 1, Fig. 1). On the other hand, the abundance of $P$. nigra showed a weak, 
unexpected and significant relationship with the LOF levels considered, being more abundant in transects with higher levels of LOF (Tab. 1, Fig. 1). A. aquaticus was more abundant when sampled with deep net (Tab. 1 and Fig. 2). No significant effect was played by the LOF levels considered.

The broad implication of the present research is that LOF at the macroinvertebrate community level does not seem to affect

Table 1. Results of the GLMMs analysis. In bold the significant results. LOF represents the level of landscape of fear.

\begin{tabular}{llll}
\hline \multicolumn{1}{c}{ Variables } & Estimate & $z$ & $P$ \\
\hline Asellus aquaticus & & & \\
Night & 0.22 & 1.05 & 0.29 \\
LOF & 0.85 & 0.31 & 0.75 \\
Deep netting & 1.23 & 5.44 & $<0.001$ \\
& & & \\
Dendrocoelum lacteum & & & \\
Night & 0.72 & 2.79 & $<0.01$ \\
LOF & 0.09 & 0.05 & 0.95 \\
Deep netting & 0.14 & 0.56 & 0.57 \\
nigra & & & \\
Polycelis night & 0.44 & 1.52 & 0.12 \\
LOF & 7.02 & 1.96 & 0.04 \\
Deep netting & 0.15 & 0.55 & 0.58 \\
\hline
\end{tabular}

the activity of macroinvertebrate foragers. On the other side the abundance of both macroinvertebrate predators and prey is strongly related to diel activity and microhabitat irrespective to their position on the food web and to LOF levels.

The ecological study of LOF is increasingly being recognised as central in understanding the patterns driving predator-prey interactions (Gallagher et al., 2017). LOF can determine the population density of a species, but interspecific competitive/predatory interactions in complex communities may produce various combinations of impacts (Gallagher et al., 2017; Manenti and Pezzoli, 2019). In freshwaters, LOF is known to determine different avoidance behaviours, like the diel vertical migrations in zooplankton (Gilbert, 2017). Both predator visual cues and kairomones are known to affect the behaviour of different freshwater prey, as example the predation risk can reduce the biomass of macroinvertebrates colonising new freshwater habitats (Marino et al., 2016). However, our study suggests that further work is in order. From one side mesopredator taxa considered in our study may not be the most important determinants of the LOF in the system that hosts native fish and alien crayfish as top predators. Often top predators feed on mesopredators with which they share prey (Rodriguez-Lozano et al., 2015) with likely LOF top-down control on both mesopredator and prey. Thus, a finer scaled characterisation of LOF levels based on the foraging activity of top wanderer predators like fish and crayfish may reveal different patterns.

Moreover, some of our results suggest that the evaluation of LOF for planarians on the basis of the available information
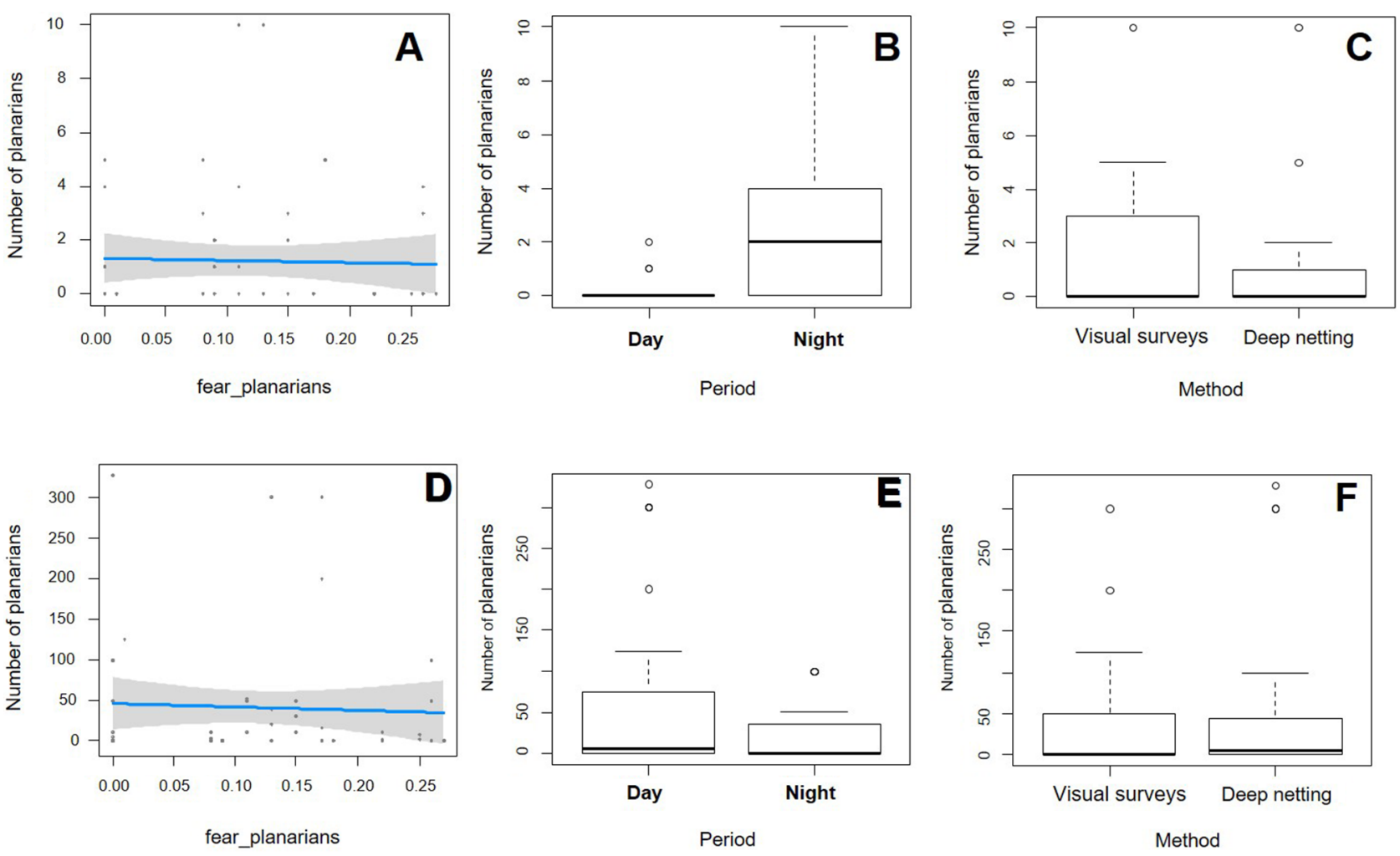

Fig. 1. Plots and boxplots of the relationship between the number of planarians of the species Dendrocoelum lacteum and Polycelis nigra and the parameters studied. A, B and C refer to Dendrocoelum lacteum; D, E and F to Polycelis nigra. Fear_planarians indicates the level of landscape of fear for the planarians. 
R. Manenti and B. Barzaghi: Knowl. Manag. Aquat. Ecosyst. 2020, 421, 8
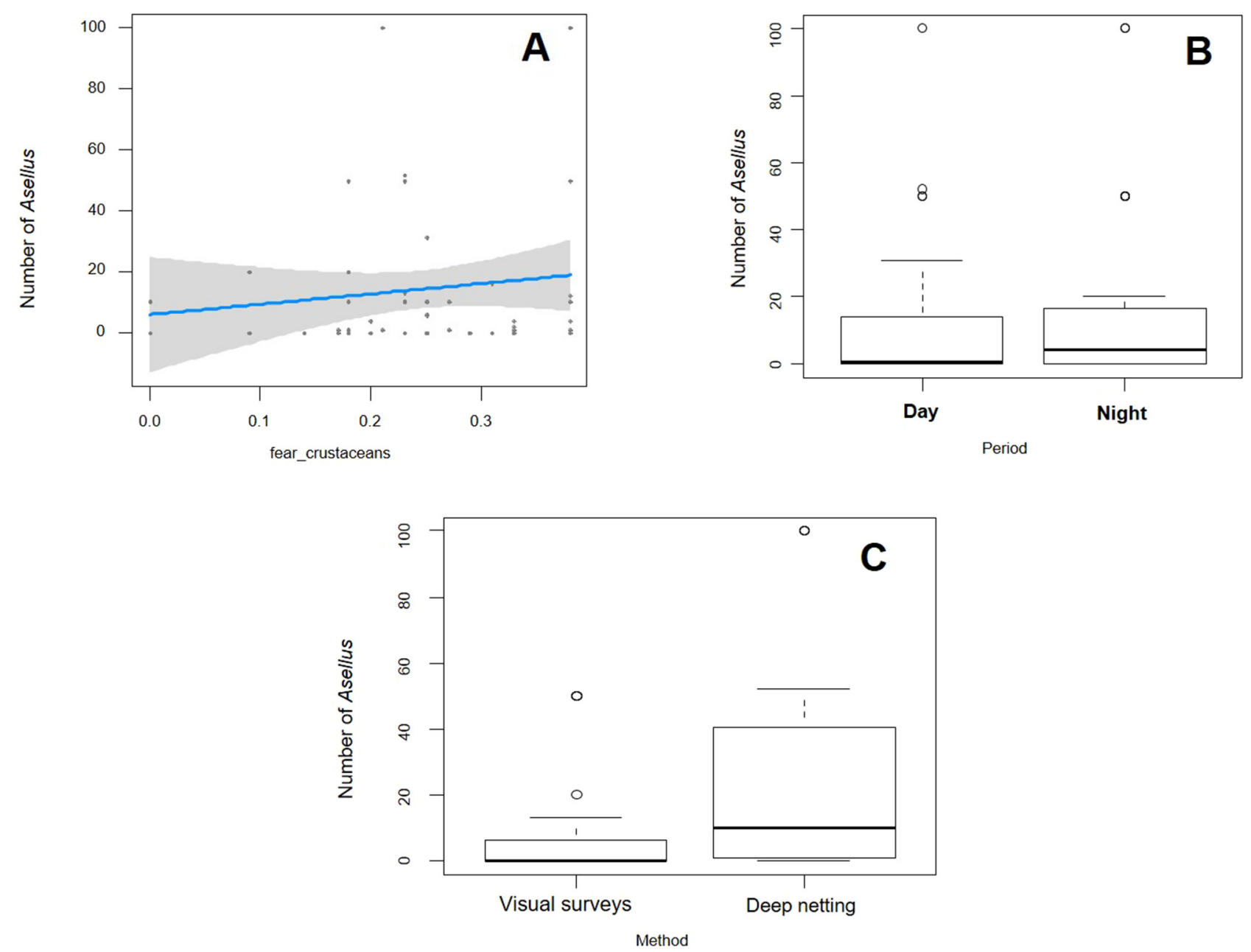

Fig. 2. Plots and boxplots of the relationship between the number of crustaceans of the species Asellus aquaticus. Fear_crustaceans indicates the level of landscape of fear for the target taxon.

could not be sufficiently reliable. It is possible that $P$. nigra is an opportunistic mesopredator feeding on already damaged/ dead invertebrates and thus favoured by other mesopredator occurrence.

A second argument of discussion originating from our results is the differential effect played by day/night conditions on the invertebrate target species. The abundance of individuals belonging to the unpigmented Dendrocoelum lacteum species is slightly higher during night. D. lacteum is an unpigmented epigean species for which some general ecological study has been performed (Reynoldson and Young, 2000); however, no detailed behavioural information exist and our results indicate that between different genera and species slight differences in the diel activity may occur. As we have argued elsewhere the study of LOF in freshwater environments may be considered a promising aspect to understand evolutionary and ecological patterns shaping freshwater organisms' distribution. Our results suggest however that more studies are necessary to increase the knowledge of species composing the macrobenthic community and that the potential role of top predators should be accounted at different habitat scales.
Acknowledgments. The research has been funded by The Mohamed Bin Zayed Species Conservation Fund, p.n. 180520056. We thank Enrico Pezzoli, Pietro Pozzoli and the Comitato Bevere ong for help. Serena Ghioni and two anonymous reviewers commented on a previous version of the manuscript.

\section{References}

Balderacchi M, Perego A, Lazzari G, Munoz-Carpena R, et al. 2016. Avoiding social traps in the ecosystem stewardship: The Italian Fontanile lowland spring. Sci Total Environ 539: 526-535.

Barker RJ, Schofield MR, Link WA, Sauer JR. 2017. On the reliability of N-Mixture models for count data. Biometrics 74: 369-377.

Brooks ME, Kristensen K, van Benthem KJ, et al. 2017. glmmTMB Balances Speed and Flexibility Among Packages for Zero-inflatedn Generalized Linear Mixed Modeling. RJ 9: 378-400.

Elliott JM. 2002. A quantitative study of day-night changes in the spatial distribution of insects in a stony stream. J Anim Ecol 71: $112-122$. 
R. Manenti and B. Barzaghi: Knowl. Manag. Aquat. Ecosyst. 2020, 421, 8

Fiser C, Keber R, Kerezi V, et al. 2007. Coexistence of species of two amphipod genera: Niphargus timavi (Niphargidae) and Gammarus fossarum (Gammaridae). J Nat Hist 41: 2641-2651.

Gallagher AJ, Creel S, Wilson RP, Cooke SJ. 2017. Energy landscapes and the landscape of fear. Trends Ecol Evol 32: 88-96.

Ghetti PF. 1997. Indice Biotico Esteso (I.B.E.): Manuale di applicazione. Provincia Autonoma di Trento, Trento. 222 p.

Gilbert JJ. 2017. Non-genetic polymorphisms in rotifers: environmental and endogenous controls, development, and features for predictable or unpredictable environments. Biol Rev 92: 964-992.

Manenti R, Pezzoli E. 2019. Think of what lies below, not only of what is visible above, or: a comprehensive zoological study of invertebrate communities of spring habitats. Eur Zool $J$ 86: 272-279.
Marino NAC, Srivastava DS, Farjalla VF. 2016. Predator kairomones change food web structure and function, regardless of cues from consumed prey. Oikos 125: 1017-1026.

Matassa CM, Trussell GC. 2011. Landscape of fear influences the relative importance of consumptive and nonconsumptive predator effects. Ecology 92: 2258-2266.

Reynoldson JD, Young JO. 2000. A key to the freshwater triclads of Britain and Ireland with notes on their ecology. Ambleside: Freshwater Biological Association, p. 72.

Rodriguez-Lozano P, Verkaik I, Rieradevall M, Prat N. 2015. Small but powerful: top predator local extinction affects ecosystem structure and function in an intermittent stream. PLOS ONE 10: e0117630.

Tachet H. 2010. Invertébrés d'eau douce : Systématique, biologie, écologie. Paris: CNRS.

Cite this article as: Manenti R, Barzaghi B. 2020. Is landscape of fear of macroinvertebrate communities a major determinant of mesopredator and prey activity? Knowl. Manag. Aquat. Ecosyst., 421, 8. 